\title{
Risk of Recurrence and Metastasis for Patients with TINOMO Esophageal Carcinoma Who Achieve Completed Resection via Endoscopic Submucosal Resection: Evidence for the Appropriateness of the Watch and Wait Follow-Up Strategy
}

This article was published in the following Dove Press journal: Cancer Management and Research

Li-Hua Zhu, ${ }^{1, *}$ Jun Yao, ${ }^{2, *}$ Ting Wu, ${ }^{3}$ Yan Wang,' Chen-Wei Wang,' Chun-Quan Xue,' Li-Guang Wu,' Xing-Wen Fan, ${ }^{4}$ Chao-Yang Wu (iD ${ }^{1}$

'Department of Radiation Oncology, The People's Hospital Affiliated to Jiangsu University, Zhenjiang, Jiangsu Province 212003, People's Republic of China; ${ }^{2}$ Department of Gastroenterology, The People's Hospital Affiliated to Jiangsu University, Zhenjiang, Jiangsu Province 212003, People's Republic of China; ${ }^{3}$ Department of Pathology, The People's Hospital Affiliated to Jiangsu University, Zhenjiang, Jiangsu Province 212003, People's Republic of China; ${ }^{4}$ Department of Radiation Oncology, Fudan University Shanghai Cancer Center, Shanghai 200032, People's Republic of China

*These authors contributed equally to this work

Correspondence: Chao-Yang Wu Department of Radiation Oncology, The People's Hospital Affiliated to Jiangsu University, Dianli Road 8 In, Zhenjiang, Jiangsu Province 212003, People's

Republic of China

Tel +86 5II 889I504I

Email wuchaoyang9@।63.com

Xing-Wen Fan

Department of Radiation Oncology,

Shanghai Cancer Center, Fudan

University, 270 Dong'an Road, Shanghai

200032, People's Republic of China

Tel +86 I365I669687

Email wenxingfan@।26.com
Purpose: Endoscopic submucosal dissection (ESD) is a widely performed procedure for esophageal carcinoma when the depth of invasion reaches the epithelium and lamina propria. However, ESD for esophageal carcinoma with depth of invasion exceeding the muscularis mucosa is controversial. This study aimed to evaluate the long-term outcomes of ESD for T1N0M0 (tumor invading the mucosa and submucosa [T1], no regional lymph node metastasis [N0], no distant metastasis [M0]) esophageal cancer.

Patients and Methods: Esophageal cancer was evaluated via pathology and computed tomography (CT) in consecutive patients with negative margin and without additional therapy. A total of 84 patients were included. The mean follow-up time was 42 (range, 9-99) months.

Results: No recurrence and metastasis were detected in the M1 and M2 group. The 5-year locoregional recurrence rate and distant metastasis rate were $4.2 \%$ and $5.6 \%$ for the M3 group and were $0 \%$ and $1.4 \%$ for the SM group, respectively. The 3- and 5-year overall survival were 94.4\% (M1+M2 group, 95.0\%; M3 group, 95.0\%; SM group, 92.9\%) and $80.9 \%$ (M1+M2 group, 95.0\%; M3 group, 95.0\%; SM group, 92.9\%). Meanwhile, the 3- and 5-year disease-specific survival rates were 100\% (M1+M2 group, 100\%; M3 group, 100\%; SM group, 100\%) and 90.8\% (M1+M2 group, 100\%; M3 group, 90.0\%; SM group, 85.7\%). The major complications were postoperative strictures, most of which were grade $1-2$. In total, two $(4.8 \%)$ and one $(1.2 \%)$ patient developed grade 3 and 5 late esophageal strictures, respectively.

Conclusion: ESD complete resection yields low recurrence and metastasis rates in early esophageal cancer (T1N0M0). Thus, additional treatment is not necessary, and a watch and wait strategy may be reasonable.

Keywords: esophageal carcinoma, endoscopic therapy, endoscopic submucosal resection, recurrence and metastasis

\section{Introduction}

Approximately 572,000 incident cases of esophageal carcinoma and 509,000 related deaths have been reported in 2018. ${ }^{1}$ Given the generally poor outcomes of patients with advanced-stage esophageal carcinoma despite surgical resection, chemotherapy, 
radiotherapy or combination therapies, ${ }^{2}$ emphasis is put on early diagnosis and treatment of premalignant lesions and early-stage esophageal cancer. An increasing number of earlystage esophageal carcinoma has been detected recently owing to aggressive screening programs that use new diagnostic endoscopic technologies, including magnification endoscopy or narrow band imaging (NBI). ${ }^{3,4}$ Significant improvements have also been achieved in endoscopic treatment, including the development of endoscopic mucosal resection (EMR) and endoscopic submucosal dissection (ESD).These modalities allowed to maintain the integrity of the esophagus and avoid esophagectomy, which is associated with high treatmentrelated morbidity and mortality. ${ }^{5,6}$

However, esophagectomy remains to be advantageous in removing all the neoplastic tissue and potentially affected lymph nodes. Meanwhile, endoscopic treatment essentially involves local resection without treatment of the lymph nodes. However, the risk of lymph node metastasis is important for prognosis. When the depth of invasion in esophageal carcinoma exceeds the epithelium (M1) and lamina propria (M2), the risk of lymph node metastases is low. The rate of local or distant recurrence and death following endoscopic therapy treatment is also low and thus additional treatment is not needed. ${ }^{7}$ However, the necessity of additional treatment after ESD for esophageal cancer with a depth of invasion exceeding the muscularis mucosa (M3), particularly among patients who achieved complete resection is controversial. Previous studies on surgery and EMR reported rates of lymph node invasion of $8.0 \%-18.0 \%, 11.0 \%-53.1 \%$ and $30.0 \%-53.9 \%$, for early esophageal carcinoma limited to M3, SM1 and SM2SM3, respectively ${ }^{8-10}$. However, radiographic metastasis could be ruled out before ESD, but not before surgery, and it is easier to achieve radical resection via ESD than EMR. ${ }^{11}$ Therefore, the long-term outcomes of ESD in patients who achieved complete resection and without additional treatments is a more reliable outcome measure. However, studies evaluating the long-term outcomes of ESD in these patients are lacking. Thus, this study aimed to investigate the prognosis and long-term outcomes of esophageal cancer patients who achieve complete resection via ESD and did not receive additional treatment.

\section{Materials and Methods}

\section{Patients}

We retrospectively analyzed patients undergoing ESD for esophageal carcinoma between October 2009 and December 2017 at our center. Those in whom distant or local lymph node metastasis was evaluated via thoracoabdominal computed tomography (CT) prior to ESD were included. Positive lymph node invasion was defined as supraclavicular lymph nodes larger than $0.5 \mathrm{~cm}$ in diameter, ${ }^{10}$ tracheoesophageal sulcus lymph nodes seen, and mediastinal lymph nodes larger than $0.5 \mathrm{~cm}$ in diameter. ${ }^{10}$ The exclusion criteria were as follows: (1) pathologically diagnosed malignancy and premalignant lesions (high-grade intraepithelial neoplasia); (2) unavailable for follow-up; (3) prior or concomitant malignancy; (4) positive lateral margins; and (5) history of surgery, radiotherapy, chemotherapy, or combined treatment. All patients with positive margins and ESD patients with T1b lesions were recommended to receive adjuvant therapy. Notably, because they refused additional treatments, some patients with histologically proven esophageal carcinoma that exceed the M3 with negative margins and negative lympho-vascular invasion were also included in the study. The study was conducted in accordance with the Helsinki Declaration and the protocol was approved by the Ethics Review Board of The People's Hospital Affiliated to Jiangsu University. All the patients signed informed consent. Tumor staging and location of esophageal cancer were described according to the 8th edition of the American Joint Committee on Cancer TNM classification. $^{12}$

\section{ESD Procedure}

All ESDs were performed under general anesthesia with endotracheal intubation and were conducted by any one of only three doctors who had 10 years' experience in endoscopic operation and have performed a combined number of at least 30 ESDs before this study. General anesthesia was induced with fentanyl citrate, and was maintained with propofol. First, the lesion was detected via white light endoscopy, and was carefully observed under NBI and iodine staining. Next, the margins were marked using a dual knife (KD-650Q, Olympus, Tokyo, Japan). A liquid mixture of glycerin fructose and indigo carmine was injected submucosally outside $0.5 \mathrm{~cm}$ of the mark. After lifting the submucosa, a caudal incision from the upper edges of the circumference was made for submucosal injection using a dual knife (KD-650Q; Olympus) or insulated-tip knife (KD-611L; Olympus) or hook knife (KD-620LR; Olympus). A complete en bloc resection defined as one-piece resection was subsequently performed. Finally, wound hemostasis was carefully performed using hemostatic forceps (FD-410LR, Olympus). The knives used during marking, mucosal incision, and submucosal dissection were according to the endoscopists' choice. 


\section{Histological Assessment}

The resected specimens were cut into 2-mm slices after fixation in $10 \%$ formalin for $24 \mathrm{hrs}$, then paraffin embedded and stained with hematoxylin and eosin. All specimens were analyzed by two expert pathologists.

The endoscopic type of the lesion was assessed according to the Paris endoscopic classification. ${ }^{13}$ Intramucosal tumors (pT1a) were distinguished as tumors invading the epithelium (M1), lamina propria (M2), or muscularis mucosae (M3). Submucosal tumors (pT1b) were also further divided into three categories: SM1 (shallower onethird of the submucosa), SM2 (middle one-third of the submucosa), and SM3 (deeper one-third of the submucosa). Tumors were graded as well-differentiated (G1), moderately differentiated (G2), and undifferentiated (G3).

\section{Follow-Up}

The typical follow up comprised CT and gastrointestinal endoscopy every 3 months during the first year after completion of ESD, every 6 months for the next 2 years, and then annually until 5 years. For patients with an invasion depth beyond the M3, positive vertical margin, and with lymphovascular invasion, additional surgical resection or chemoradiotherapy was recommended. However, some patients refused additional treatment because of fear of comorbidities. Histological and/or explicit radiological proof was required before diagnosis of recurrence. Local and regional recurrences were defined as recurrences within the esophagus, and within the regional lymph nodes, respectively. ${ }^{14}$ Distant metastasis was defined as non-regional lymph node metastases and any distant organ metastases.

\section{Complication}

All adverse events, including treatment-related esophageal stricture, were evaluated according to the Common Terminology Criteria for Adverse Events (CTCAE) version 3.0.

\section{Statistical Analysis}

Data were presented as median value and range or number (\%). Survival curves were compared using the Log-rank test. Overall survival (OS) was calculated from the date of ESD until death or last follow-up. Disease-specific survival (DSS) was calculated from the date of ESD until death due to esophageal carcinoma or last follow-up. The rates of locoregional recurrence and distant metastasis were calculated from the date of ESD to the time of first locoregional and distant metastasis, respectively. Kaplan-Meier analysis was used to evaluate survival probabilities All statistical analyses were performed using SPSS version 20. A twosided P-value less than 0.05 was considered significant.

\section{Results}

\section{Baseline Characteristics}

Of the 103 consecutive patients identified, we excluded 19 patients because they could not follow-up $(n=1)$, had prior or concomitant malignancy $(n=3)$, or had a positive margin and received other treatments such as surgery, radiotherapy, chemotherapy or combined treatment $(n=15)$. Finally, 84 patients were enrolled. In total, 89 lesions were resected (Figure 1). All patients achieved complete resection (histologically confirmed tumor-negative margins and negative lympho-vascular invasion) and had no additional treatments. Table 1 shows the patients' demographic and tumor characteristics. Tumor multifocality was seen in $6 / 84$ patients $(7 \%)$, four patients showed moderate to high-grade dysplasia of squamous epithelium in the esophagus, one patient had three lesions that were all moderate-grade squamous cell carcinoma, and one patient had highly to moderately differentiated tubular adenocarcinoma in the cardia.

\section{Recurrence Pattern}

he data were last updated in October 2018, and the median follow-up for the whole cohort was 42 (range, 9-99) months. At the time of this analysis, a total of four patients (4.8\%) developed recurrences; the details of the recurrence sites are summarized in Table 2. Two patients $(2.3 \%)$ experienced local recurrence in the esophagus, and their lesions were located in the lower thoracic esophagus. One patient with local recurrence underwent salvage surgery and developed no recurrence or metastasis on follow-up. However, an 82year-old patient who had in-situ recurrence and discontinued surgery or chemoradiotherapy died 4 months after the detection of recurrence. One patient (1.2\%) whose lesions were located in the middle thorax had supraclavicular recurrences without evidence of any other site failure, died after salvage chemoradiotherapy. One patient experienced bone metastasis and died without chemoradiotherapy. No recurrence and metastasis was detected in the M1 and M2 group, and the primary site in all recurrent cases was located in the middle and lower esophagus. The 5-year recurrence rate and metastasis rate for the $\mathrm{M} 3$ group were $4.2 \%$ and $5.6 \%$, respectively. The 5-year recurrence rate and metastasis rate for the SM group were $0 \%$ and $1.4 \%$, respectively. Meanwhile, there 


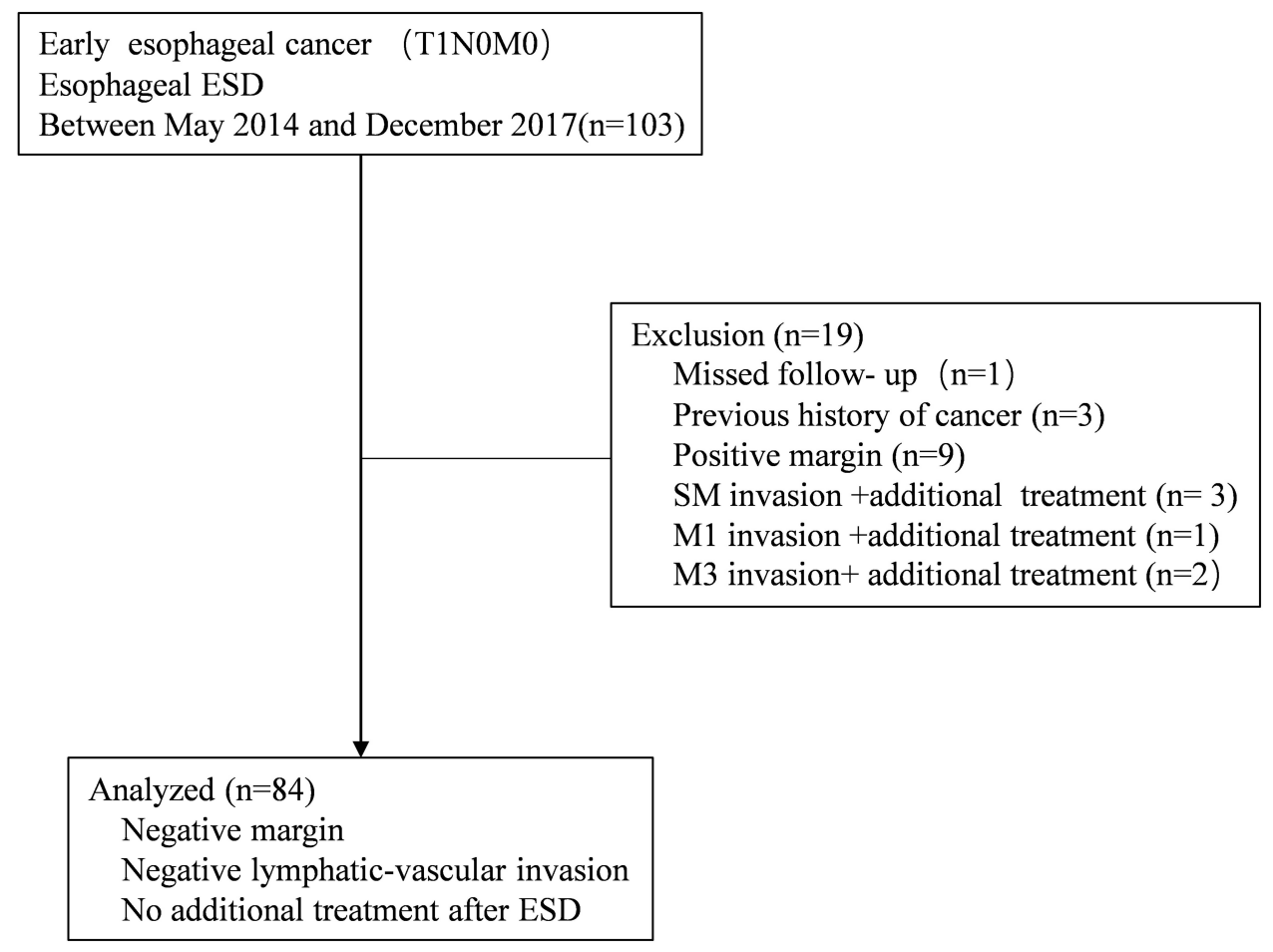

Figure I Diagram of the study design.

Abbreviations: ESD, endoscopic submucosal dissection; MI, epithelium; M2, lamina propria; M3, muscularis mucosa; SM, submucosal.

were no significant differences in recurrence rate $(P=0.432)$ and metastasis rate $(P=0.354)$ between the $\mathrm{M} 1+\mathrm{M} 2$, M3 and SM groups (Figure 2).

\section{Survival}

The long-term outcomes of the 84 patients at the last follow-up visit shown in Figure 3. The median follow-up for the M1+M2 group, the M3 group and the SM group was 32 (range, 9-97) months, 43 (range, 9-99) months and 48 (range, 12-99) months, respectively. Although no recurrence and metastasis were detected in the M1 and M2 group, there was no significant difference in OS and DSS between the M1+M2 group, the M3 group and the SM group ( $P=0.579, P=0.278$ ) (Figure 3$)$. The 3 - and 5 -year OS in the overall population were $94.4 \%$ (M1 +M2 group, 95.0\%; M3 group, 95.0\%; SM group, 92.9\%) and $80.9 \%$ (M1+M2 group, 95.0\%; M3 group, 95.0\%; SM group, 92.9\%), respectively. Meanwhile, the 3- and 5-year DSS rates were 100\% (M1+M2 group, $100 \%$; M3 group, $100 \%$; SM group, $100 \%$ ) and $90.8 \%$ (M1+M2 group, 100\%; M3 group, 90.0\%; SM group, $85.7 \%$ ), respectively. Only three patients died of esophageal cancer. The other causes of death included lung cancer $(n=1)$, leukocythemia $(n=1)$, pancreatic cancer $(n=1)$, cardiovascular disease-related deaths $(n=3)$, and esophageal stricture $(\mathrm{n}=1)$.

\section{Complications}

No perforations occurred in any procedures. The mean blood loss was 3 (range, 2-5) $\mathrm{mL}$. Delayed bleeding occurred in one of the procedures and was successfully treated via endoscopy. The rate of postoperative strictures was $11.9 \%(10 / 84)$. Four patients with strictures were successfully treated with endoscopic dilatation, and were able to eat soft food. Severe esophageal stricture as an adverse effect of ESD was observed in one patient after several endoscopic dilations. Only one patient developed severe stenosis, with lesions located in the lower thorax that invaded the muscularis mucosa. The mucosal defect measured $3 \mathrm{~cm}$ in length and $75 \%$ of the luminal circumference. Unfortunately, the patient refused stents placement due to the cost and died from the stenosis (Table 3).

\section{Discussion}

ESD is a widely performed procedure for esophageal carcinoma when the depth of invasion reaches the epithelium and lamina propria. However, the appropriateness of follow-up treatment after ESD in cases with a depth of invasion 
Table I Clinical Characteristics of the 84 Patients

\begin{tabular}{|c|c|}
\hline Variables & $\mathbf{N}(\%)$ \\
\hline \multicolumn{2}{|l|}{ Sex } \\
\hline Female & $17(20.2)$ \\
\hline Male & $67(79.8)$ \\
\hline \multicolumn{2}{|l|}{ Age (years) } \\
\hline Median (range) & $67(46-86)$ \\
\hline$<55$ & II (I3.I) \\
\hline $55-70$ & $46(54.8)$ \\
\hline$>70$ & $27(32.1)$ \\
\hline \multicolumn{2}{|l|}{ Other cancer after ESD } \\
\hline Lung cancer & $\mathrm{I}(\mathrm{I} .2)$ \\
\hline Pancreatic-cancer & $\mathrm{I}(\mathrm{I} .2)$ \\
\hline Leukemia & $\mathrm{I}(\mathrm{I} .2)$ \\
\hline Total & $3(3.6)$ \\
\hline \multicolumn{2}{|l|}{ Gross tumor size $(\mathrm{cm})$} \\
\hline Median (range) & $2.4(1.0-8.0)$ \\
\hline$<2.0$ & $30(35.7)$ \\
\hline $2.0-4.0$ & $46(54.8)$ \\
\hline$>4$ & $8(9.5)$ \\
\hline \multicolumn{2}{|l|}{ Tumor location } \\
\hline Cervical & $2(2.4)$ \\
\hline Upper thoracic & $9(10.7)$ \\
\hline Mid-thoracic & $25(29.8)$ \\
\hline Lower thoracic & $45(53.6)$ \\
\hline Gastroesophageal junction & $3(3.6)$ \\
\hline \multicolumn{2}{|l|}{ Lumen circumference } \\
\hline$\leqq 1 / 3$ & $51(60.7)$ \\
\hline$>1 / 3, \leqq 3 / 4$ & $28(33.3)$ \\
\hline$\geqq 3 / 4$ & $5(6.0)$ \\
\hline \multicolumn{2}{|l|}{ Tumor morphology } \\
\hline I & $\mathrm{I}(\mathrm{I} .2)$ \\
\hline Ila & $15(17.9)$ \\
\hline Ilb & $65(77.4)$ \\
\hline IIc & $3(3.6)$ \\
\hline \multicolumn{2}{|l|}{ Histology } \\
\hline Squamous cell carcinoma & $82(97.6)$ \\
\hline Adenocarcinoma & $\mathrm{I}(\mathrm{I} .2)$ \\
\hline Sarcoma & $\mathrm{I}(\mathrm{I} .2)$ \\
\hline \multicolumn{2}{|l|}{ Differentiation } \\
\hline GI & $26(31.0)$ \\
\hline G2 & $50(59.5)$ \\
\hline G3 & $7(8.3)$ \\
\hline Unknown & $\mathrm{I}(\mathrm{I} .2)$ \\
\hline \multicolumn{2}{|l|}{ Depth of tumor infiltration } \\
\hline MI & $19(22.6)$ \\
\hline M2 & $5(6.0)$ \\
\hline M3 & $43(5 \mid .2)$ \\
\hline
\end{tabular}

(Continued)
Table I (Continued).

\begin{tabular}{|l|l|}
\hline Variables & N (\%) \\
\hline SMI & $\mathrm{I}(1.2)$ \\
SM2 & $2(2.4)$ \\
SM3 & $14(16.7)$ \\
\hline Lympho-vascular involvement & \\
Positive & $0(0)$ \\
Negative & $84(100)$ \\
\hline Follow-up & \\
Median (range) & $42(9-99)$ \\
\hline
\end{tabular}

exceeding the muscularis mucosa is controversial. In this study, we observed patients who underwent ESD for T1N0M0 (tumor invading the mucosa and submucosa[T1], no regional lymph node metastasis [N0], no distant metastasis [M0]) esophageal carcinoma and achieved negative margins and received no additional treatment. The rate of recurrence and metastasis was extremely low, no recurrence and metastasis was detected in the M1 and the M2 groups, only two cases developed local recurrence, and only two cases in the M3 and SM group developed distant metastasis. The 5-years DSS was also excellent. These results support that watch and wait strategy after ESD could be implemented in esophageal cancer patients who achieve complete resection and receive no additional treatments. To the best of our knowledge, our study is the first large-scale, long-term study to directly investigate outcomes in these patients.

However, our findings are in contrast to those of previous studies, based on surgery and EMR, which reported rates lymph node invasion of $8.0 \%-18.0 \%, 11.0 \%-53.1 \%$, and $30.0 \%-53.9 \%$ for early esophageal carcinoma limited to the M3, SM1 and SM2-SM3, respectively. ${ }^{8-10}$ Studies on EMR resection reported disease recurrence rates from 2.4\%-26\%. ${ }^{15-18}$ The National Comprehensive Cancer Network guidelines recommend additional treatments such as surgery or chemoradiotherapy to prevent locoregional progression and metastasis, after ESD for M3 or T1b tumors. We found that complete resection via ESD for M3 and SM with negative margin and negative lymphovascular invasion yields low recurrence and metastasis rates, and thus a watch and wait strategy would be reasonable. Clinicians should consider avoiding surgery or chemoradiotherapy as salvage therapy to avoid excessive treatments. However, the optimal treatment strategies for these patients need to be confirmed in prospective studies. 
Table 2 Clinical Features of the Patients Who Recurred After ESD

\begin{tabular}{|c|c|c|c|c|c|c|c|c|c|c|c|c|}
\hline Patient & Pattern of Failure & Age, Years & Sex & $L^{\prime}$ & Size, cm & Depth & $M^{2}$ & $D^{3}$ & $c^{4}$ & $\mathbf{H}^{5}$ & PFS & os \\
\hline I & Recurrence in situ & 68 & M & $\mathrm{Lt}$ & I & M3 & Ila & G2 & $1 / 3$ & SCC & 35 & 43 \\
\hline 2 & Recurrence in situ & 75 & M & Lt & 5 & SMI & Ilb & GI & $1 / 2$ & SCC & 83 & 86 \\
\hline 3 & Supraclavicular lymph node metastasis & 46 & M & $\mathrm{Gj}$ & 2 & M3 & $\mathrm{llb}$ & G2 & $2 / 3$ & SCC & 49 & 51 \\
\hline 4 & Bone metastases & 69 & $\mathrm{~F}$ & Mt & 2 & SM3 & Ilb & G2 & $1 / 2$ & SCC & 40 & 55 \\
\hline
\end{tabular}

Notes: I, Location; 2, Paris classification; 3, Depth; 4, Circumferential extent as a proportion of the entire esophageal circumference; 5, Histology.

Abbreviations: F, female; M, male; Mt, middle thoracic; Lt, lower thoracic; Gj, gastroesophageal junction; SCC, squamous cell carcinoma.

The low rates of recurrence in our study may be closely related to the inclusion criterion in our cohort. First, ESD, not EMR, was used for endoscopic resection of esophageal lesions in all patients. Although there have been on the long-term outcomes of endoscopic resections, ${ }^{17,19}$ these studies included heterogeneous groups of patients treated via ESD and EMR.
Compared with ESD, EMR has higher local recurrences as a result of inaccuracies in assessment of margin, invasion depth, and lympho-vascular involvement. ${ }^{11}$ Furthermore, ESD was associated with a higher recurrence-free survival in infiltrative tumors. ${ }^{20}$ Second, all ESDs were conducted under general anesthesia and performed by only one of three doctors
A

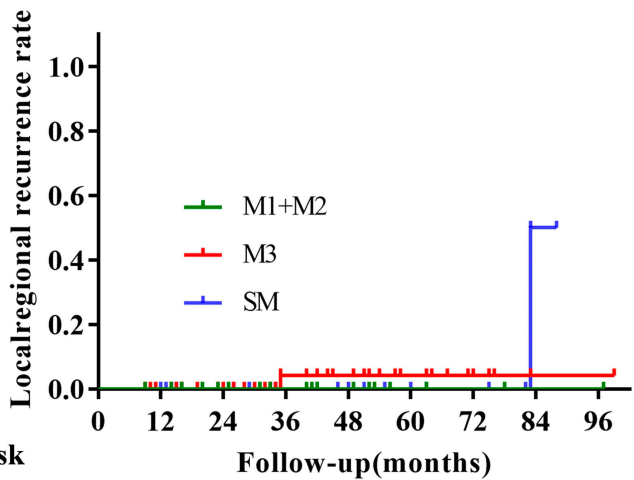

Number at risk

$\begin{array}{rrrrrlllll}\text { M1+M2 } & 24 & 24 & 15 & 12 & 9 & 4 & 3 & 2 & 2 \\ \text { M3 } & 43 & 40 & 31 & 24 & 20 & 12 & 6 & 2 & 2 \\ \text { SM } & 17 & 17 & 14 & 12 & 9 & 6 & 4 & 2 & 1\end{array}$

B

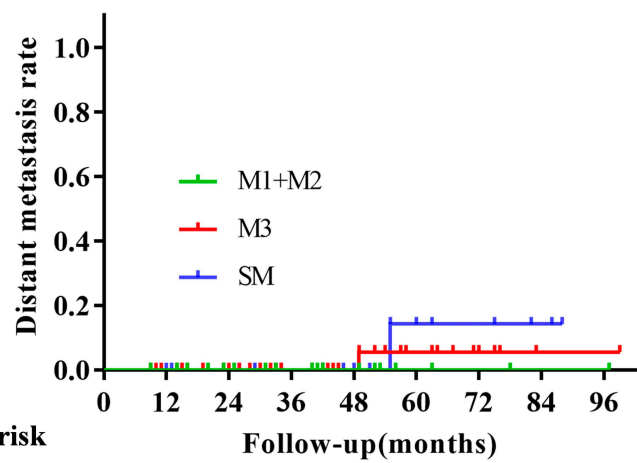

$\begin{array}{cccccccccc}\mathrm{M} 1+\mathrm{M} 2 & 24 & 24 & 15 & 12 & 9 & 4 & 3 & 2 & 2 \\ \mathrm{M} 3 & 43 & 40 & 31 & 25 & 20 & 12 & 6 & 2 & 2 \\ \mathrm{SM} & 17 & 17 & 15 & 12 & 9 & 6 & 5 & 2 & 1\end{array}$

Figure 2 The rate of locoregional recurrence $(\mathbf{A})$ and the rate of distant metastasis $(\mathbf{B})$ for every group.

A

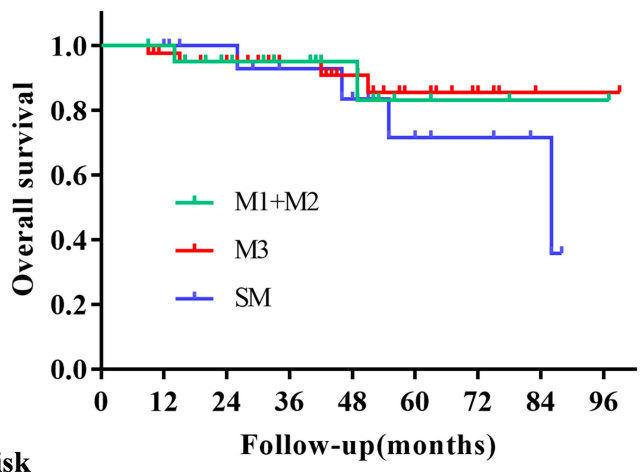

Number at risk

$\begin{array}{cccccccccc}\mathrm{M} 1+\mathrm{M} 2 & 24 & 24 & 15 & 12 & 9 & 4 & 3 & 2 & 2 \\ \mathrm{M} 3 & 43 & 40 & 25 & 31 & 20 & 12 & 6 & 2 & 2 \\ \mathrm{SM} & 17 & 17 & 15 & 12 & 9 & 6 & 5 & 2 & 1\end{array}$

B

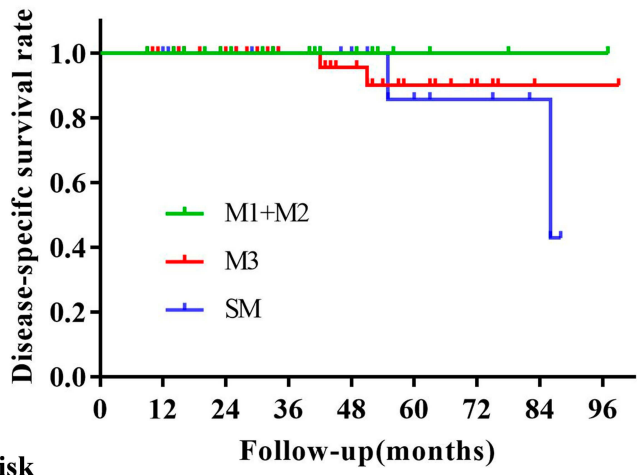

Number at risk

$\begin{array}{rrrrrrrrrr}\text { M1+M2 } & 24 & 24 & 15 & 12 & 9 & 4 & 3 & 2 & 2 \\ \text { M3 } & 43 & 40 & 25 & 25 & 20 & 12 & 6 & 2 & 2 \\ \text { SM } & 17 & 17 & 15 & 12 & 9 & 6 & 5 & 2 & 1\end{array}$

Figure 3 Overall survival (A) and disease-specific survival (B) for every group. 
Table 3 Complications of Endoscopic Submucosal Dissection

\begin{tabular}{|l|l|}
\hline Complications & N (\%) \\
\hline Perforation & $0(0)$ \\
Delayed bleeding & $\mathrm{I}(\mathrm{I} .2 \%)$ \\
\hline Postoperative strictures & $10(11.9 \%)$ \\
Grade I & $3(3.6 \%)$ \\
Grade 2 & $2(2.4 \%)$ \\
Grade 3 & $4(4.8 \%)$ \\
Grade 4 & $0(0)$ \\
Grade 5 & $\mathrm{I}(\mathrm{I} .2 \%)$ \\
\hline
\end{tabular}

who had 10 years' experience in endoscopic operation, and who collectively have performed an average of 30 ESDs. Recently Song et $\mathrm{a}^{21}$ reported that conscious sedation was an independent risk factor for incomplete resection, while general anesthesia improves the outcomes of esophageal ESD. Third, no patient in our cohort had pathologically confirmed lymphovascular involvement, and we excluded cases with positive margin, which are associated with cancer recurrence and metastasis. ${ }^{17,22}$

The low rates of metastasis in our study may also be attributed to our inclusion criterion. First, we excluded patients who received additional treatment following ESD. Complementary chemoradiotherapy has been reported to lower the risk of nodal or distal metastasis associated with infiltrative tumors, ${ }^{23,24}$ and patients could also benefit from ESD combined with additional treatment ${ }^{25}$. Second, ESD patients were strictly selected according to $\mathrm{CT}$ assessments. We excluded patients with positive radiographic lymph nodes which was not conducted in previous studies on surgery. ${ }^{26-29}$ However, it should be noted that with respect to morphology assessed via endoscopy, only one type I case and no type III tumor was included in the cohort. Recently Takubo et $\mathrm{al}^{30}$ reported a higher incidence of lymph node metastasis in type I and III tumors. Lastly, all ESD specimens were cut into 2-mm sections, whereas surgical specimens are cut to $5-\mathrm{mm}$ sections. Thinly slicing specimens provide a more detailed evaluation of vessel invasion for precise pathological diagnosis ${ }^{11}$. Eguchi et $\mathrm{al}^{9}$ highlighted that the risk of lymph node metastasis after lymphovascular invasion in M3 and SM1 lesions increased from $10.3 \%$ and $28.9 \%$ to $41.7 \%$ and $100 \%$, respectively, and follow-up results also suggested that lympho-vascular invasion of $\mathrm{M} 3$ increased the metastasis rate from $0.7 \%$ to $46.7 \% .{ }^{17}$ In our study, we confirmed negative lymphovascular invasion after pathological assessment of the ESD specimen.
The main benefit of ESD is that it is a minimally invasive operation. In contrast to the high perioperative mortality of esophagectomy, ${ }^{6}$ ESD almost never leads to perioperative death. In this study, the incidence of complications of ESD, such as perforations, was zero. Delayed bleeding occurred in $1.2 \%$ of procedures $(1 / 84)$ and the patient was successfully treated with hemostatic drugs and blood transfusion, without the need for endoscopy. In addition, esophagectomy deeply affects short- and long-term quality of life for cancer survivors, whereas ESD does so rarely, except for those with esophageal strictures. Delayed complications in our study were mainly postoperative strictures $(11.5 \%)$, and this rate is similar to those described in recent studies. ${ }^{20}$ Treatment of benign esophageal strictures with serial endoscopic dilatation using bougies or balloons has been established as a standard therapy, and it is associated with an immediate $80-90 \%$ success rate in relieving dysphagia. ${ }^{31,32}$ Furthermore, temporary stent placement was a late step in the treatment strategy of benign esophageal strictures. ${ }^{33}$ Thus, combining ESD with followup is the ideal first choice for patients with T1N0M0 disease. Due to the high complication rate, esophagectomy may be reasonably considered as a salvage treatment.

The present study had several limitations. First, this was a retrospective, single-center study by design. Second, old patients with T1 esophageal cancer are prone to selecting $\mathrm{ESD}$; therefore, the mortality rate from secondary primary malignancy and cardiovascular disease was high, and the OS may be influenced by recurrence and metastasis. Third, although to our knowledge our cohort is one of the largest published, the number of recurrent and metastatic cases is too small for a reliable statistical analysis of subgroups. However, we divided the patients into three groups and found no major difference. Given the limited number of cases, we can only conclude that there are no significant differences between the three study groups (i.e., M1+M2, M3, and SM).

\section{Conclusion}

Complete resection via ESD for early esophageal cancer (T1N0M0) yields very low recurrence and metastasis. As such, additional treatment is not necessary. A watch and wait strategy is one of the options, depending upon the pathological result and patient condition. Prospective studies with larger samples are needed to confirm our findings.

\section{Abbreviations}

CT, computed tomography; DSS, disease-specific survival; EMR, endoscopic mucosal resection; ESD, endoscopic 
submucosal dissection; NBI, narrow band imaging; OS, overall survival.

\section{Acknowledgments}

We thank the patients participated in this study and endoscopic operator $(\mathrm{XXX})$.

\section{Funding}

This research did not receive any specific grant from funding agencies in the public, commercial, or not-for-profit sectors.

\section{Disclosure}

The authors report no conflicts of interest in this work.

\section{References}

1. Bray F, Ferlay J, Soerjomataram I, Siegel RL, Torre LA, Jemal A. Global cancer statistics 2018: GLOBOCAN estimates of incidence and mortality worldwide for 36 cancers in 185 countries. CA Cancer J Clin. 2018;68:394-424. doi:10.3322/caac.21492

2. van Hagen $P$, Hulshof MC, van Lanschot JJ, et al. Preoperative chemoradiotherapy for esophageal or junctional cancer. $N$ Engl $J$ Med. 2012;366:2074-2084. doi:10.1056/NEJMoa1112088

3. Kodashima S, Fujishiro M, Takubo K, et al. Ex-vivo study of high-magnification chromoendoscopy in the gastrointestinal tract to determine the optimal staining conditions for endocytoscopy. Endoscopy. 2006;38(11):1115-1121. doi:10.1055/s-2006-944915

4. Yoshida T, Inoue H, Usui S, Satodate H, Fukami N, Kudo SE. Narrow-band imaging system with magnifying endoscopy for superficial esophageal lesions. Gastrointest Endosc. 2004;59:288-295. doi:10.1016/S0016-5107(03)02532-X

5. Stahl M, Stuschke M, Lehmann N, et al. Chemoradiation with and without surgery in patients with locally advanced squamous cell carcinoma of the esophagus. J Clin Oncol. 2005;23(10):2310-2317. doi:10.1200/JCO.2005.00.034

6. Fuchs HF, Harnsberger CR, Broderick RC, et al. Mortality after esophagectomy is heavily impacted by center volume: retrospective analysis of the nationwide inpatient sample. Surg Endoscopy Other Intervent Tech. 2017;31(6):2491-2497. doi:10.1007/s00464-016-5251-9

7. Pech O, May A, Manner H, et al. Long-term efficacy and safety of endoscopic resection for patients with mucosal adenocarcinoma of the esophagus. Gastroenterology. 2014;146(3):652-660. doi:10.1053/ j.gastro.2013.11.006

8. Tajima Y, Tachimori Y, Tachimori Y, et al. Significance of involvement by squamous cell carcinoma of the ducts of esophageal submucosal glands. Analysis of 201 surgically resected superficial squamous cell carcinomas. Cancer. 2000;89(2):248-254. doi:10.1002/(ISSN)1097-0142

9. Eguchi T, Nakanishi Y, Shimoda T, et al. Histopathological criteria for additional treatment after endoscopic mucosal resection for esophageal cancer: analysis of 464 surgically resected cases. Mod Pathol. 2006;19:475-480. doi:10.1038/modpathol.3800557

10. Bollschweiler E, Baldus SE, Schroder W, et al. High rate of lymph-node metastasis in submucosal esophageal squamous-cell carcinomas and adenocarcinomas. Endoscopy. 2006;38(2):149-156. doi:10.1055/s-2006-924993

11. Takahashi H, Arimura Y, Masao H, et al. Endoscopic submucosal dissection is superior to conventional endoscopic resection as a curative treatment for early squamous cell carcinoma of the esophagus (with video). Gastrointest Endosc. 2010;72(2):255-264. doi:10.1016/j.gie.2010.02.040
12. Rice TW, Ishwaran H, Ferguson MK, Blackstone EH, Goldstraw P. Cancer of the esophagus and esophagogastric junction: an eighth edition staging primer. $J$ Thor Oncol. 2017;12(1):36-42. doi:10.1016/j.jtho.2016.10.016

13. Workshop PITP. The Paris endoscopic classification of superficial neoplastic lesions: esophagus, stomach, and colon: november 30 to December 1, 2002. Gastrointest Endosc. 2003;58:S3-S43. doi:10.1016/S0016-5107(03)02159-X

14. Cao CN, Liu SY, Luo JW, et al. Pattern of failure in surgically treated patients with cervical esophageal squamous cell carcinoma. Otolaryngol Head Neck Surg. 2014;151:260-264. doi:10.1177/ 0194599814531915

15. Katada C, Muto M, Manabe T, Ohtsu A, Yoshida S. Local recurrence of squamous-cell carcinoma of the esophagus after EMR. Gastrointest Endosc. 2005;61:219-225. doi:10.1016/S00165107(04)02756-7

16. Jiang D, Li X, Wang $\mathrm{H}$, et al. A retrospective study of endoscopic resection for 368 patients with early esophageal squamous cell carcinoma or precancerous lesions. Surg Endoscopy Other Intervent Tech. 2017;31:2122-2130. doi:10.1007/s00464-016-5208-z

17. Yamashina T, Ishihara R, Nagai K, et al. Long-term outcome and metastatic risk after endoscopic resection of superficial esophageal squamous cell carcinoma. Am J Gastroenterol. 2013;108(4):544-551. doi:10.1038/ajg.2013.8

18. Pech O, Gossner L, May A, Vieth M, Stolte M, Ell C. Endoscopic resection of superficial esophageal squamous-cell carcinomas: western experience. Am J Gastroenterol. 2004;99:1226-1232. doi:10.1111/j.1572-0241.2004.30628.x

19. Guo HM, Zhang XQ, Chen M, Huang SL, Zou XP. Endoscopic submucosal dissection vs endoscopic mucosal resection for superficial esophageal cancer. World J Gastroenterol. 2014;20:5540-5547. doi:10.3748/wjg.v20.i18.5540

20. Berger A, Rahmi G, Perrod G, et al. Long-term follow-up after endoscopic resection for superficial esophageal squamous cell carcinoma: a multicenter Western study. ENDOSCOPY. 2019;51:298-306. doi:10.1055/a-0732-5317

21. Song BG, Min YW, Cha RR, et al. Endoscopic submucosal dissection under general anesthesia for superficial esophageal squamous cell carcinoma is associated with better clinical outcomes. $B M C$ Gastroenterol. 2018;18:80. doi:10.1186/s12876-018-0813-z

22. Sgourakis G, Gockel I, Lang H. Endoscopic and surgical resection of T1a/T1b esophageal neoplasms: a systematic review. World J Gastroenterol. 2013;19(9):1424-1437. doi:10.3748/wjg.v19.i9.1424

23. Ikeda A, Hoshi N, Yoshizaki T, et al. Endoscopic Submucosal Dissection (ESD) with additional therapy for superficial esophageal cancer with submucosal invasion. Intern Med. 2015;54 (22):2803-2813. doi:10.2169/internalmedicine.54.3591

24. Hisano $\mathrm{O}$, Nonoshita $\mathrm{T}$, Hirata $\mathrm{H}$, et al. Additional radiotherapy following endoscopic submucosal dissection for T1a-MM/T1b-SM esophageal squamous cell carcinoma improves locoregional control. Rad Oncol. 2018;13(1):14. doi:10.1186/s13014-018-0960-y

25. Minashi K, Nihei K, Mizusawa J, et al. Efficacy of endoscopic resection and selective chemoradiotherapy for Stage I esophageal squamous cell carcinoma. Gastroenterology. 2019;157(2):382-390. e3. doi:10.1053/j.gastro.2019.04.017

26. Ancona E, Rampado S, Cassaro M, et al. Prediction of lymph node status in superficial esophageal carcinoma. Ann Surg Oncol. 2008;15 (11):3278-3288. doi:10.1245/s10434-008-0065-1

27. Sepesi B, Watson TJ, Zhou D, et al. Are endoscopic therapies appropriate for superficial submucosal esophageal adenocarcinoma? An analysis of esophagectomy specimens. J Am Coll Surg. 2010;210:418-427. doi:10.1016/j.jamcollsurg.2010.01.003

28. Leers JM, DeMeester SR, Oezcelik A, et al. The prevalence of lymph node metastases in patients with $\mathrm{T} 1$ esophageal adenocarcinoma a retrospective review of esophagectomy specimens. Ann Surg. 2011;253:271-278. doi:10.1097/SLA.0b013e3181 fbad42 
29. Barbour AP, Jones M, Brown I, et al. Risk stratification for early esophageal adenocarcinoma: analysis of lymphatic spread and prognostic factors. Ann Surg Oncol. 2010;17(9):2494-2502. doi:10.1245/ s10434-010-1025-0

30. Takubo K, Makuuchi H, Arima M, Aida J, Arai T, Vieth M. [Lymph node metastasis in superficial squamous carcinoma of the esophagus]. Pathologe. 2013;34(2):148-154. doi:10.1007/s00292-012-1730-5

31. Eloubeidi MA, Talreja JP, Lopes TL, Al-awabdy BS, Shami VM, Kahaleh M. Success and complications associated with placement of fully covered removable self-expandable metal stents for benign esophageal diseases (with videos). Gastrointest Endosc. 2011;73 (4):673-681. doi:10.1016/j.gie.2010.11.014
32. Dua KS, Vleggaar FP, Santharam R, Siersema PD. Removable self-expanding plastic esophageal stent as a continuous, non-permanent dilator in treating refractory benign esophageal strictures: a prospective two-center study. The American Journal of Gastroenterology. 2008;103(12):2988-2994. doi:10.1111/j.15720241.2008.02177.x

33. de Wijkerslooth LR, Vleggaar FP, Siersema PD. Endoscopic management of difficult or recurrent esophageal strictures. Am J Gastroenterol. 2011;106(2080-2091):2092. doi:10.1038/ajg.2011.348

\section{Publish your work in this journal}

Cancer Management and Research is an international, peer-reviewed open access journal focusing on cancer research and the optimal use of preventative and integrated treatment interventions to achieve improved outcomes, enhanced survival and quality of life for the cancer patient.
The manuscript management system is completely online and includes a very quick and fair peer-review system, which is all easy to use. Visit http://www.dovepress.com/testimonials.php to read real quotes from published authors. 